\title{
Evolution of host-parasite relation in humans
}

\author{
Ana M. Castro* \\ Departamento de Salud Pública, Facultad de Medicina, National Autonomous University of Mexico, Mexico City, Mexico
}

The relationship between the host and the parasite has been around since immemorial time. The parasites that affect humans are classified as viruses, bacteria, fungi, and parasites. The science that studies parasites is microbiology.

The Greeks (Hippocrates 460370/380 to C) knew and named the macroscopic parasites as oxyurids (Ascaris), larger roundworms (strongyles) and those with a flattened body (helminth plateia), vesicles with aqueous tissue content (hydatids). Aristotle (384322 a C) described and classified intestinal worms (helminths), and his disciple and follower, the botanist Theophrastus (372287 a C) provided information on anthelmintics, including the male fern rhizome, which he says heals the tenias. The knowledge about the active molecules of this drug served for the production of fasciolicides and modern pesticides. The Greeks inherit a good part of the Egyptian knowledge through the conquest of Alexander the Great (363-323) and the consequent dynasty of the Ptolemies, body of doctrine successively transferred to the Romans.

With the advent of the microscope, the work of a Dutch tissue merchant, Antonie van Leeuwenhoek (1632-1723) was able to identify the bacteria. In 1675, this researcher found that, in a drop of pond water, an amazing variety of small creatures swarmed, which he called "animalcules" and in 1683 he discovered the bacteria.

The intervention of bacteria as specific agents in the production of diseases was recognized as a result of a series of investigations on anthrax, a disease that affects cattle and can be transmitted to humans. C. Davaine, between 1863 and 1868, detected that large amounts of microorganisms appeared in the blood of affected cows, which he called bacteria; in addition, he managed to induce the disease experimentally in healthy cows, inoculating them with samples of infected blood. In 1872, the German doctor C.J. Eberth was able to isolate the bacilli by filtering the blood of anthrax animals. However, in 1876, it was Robert Koch (1843-1910), who had been a student of Henle, with his recent technique of pure cultivation achieved the first isolation and in vitro propagation of the anthrax bacillus (Bacillus anthracis) getting the first photomicrographs on dry preparation, fixed and stained with methylene blue. Later (1881), Koch and his collaborators confirmed that the spores are structures differentiated from the bacilli and more resistant to a variety of agents than bacilli. However, more important was his demonstration that the disease could be transmitted successively to healthy mice by inoculating them with pure culture bacilli.

This type of strategy to demonstrate the bacterial origin of the disease was taken to a further perfection in 1882, with the publication of "Die Äthiologie der Tuberkulose," where the application of the criteria that Henle had postulated in 1840 is communicated for the $1^{\text {st }}$ time. Today, these criteria are associated with the name of Koch and are called "Postulates of Koch."

On the other hand, the French School, working on the infective processes, concentrated on the immunity of the individual and obtaining of vaccines; especially
Correspondence:

${ }^{*}$ Ana M. Castro

E-mail: amcastro@unam.mx

0185-1063/@ 2019 Sociedad Médica del Hospital General de Mexico. Published by Permanyer México SA de CV. This is an open access article under the CC BY-NC-ND license (http://creativecommons.org/licenses/by-nc-nd/4.0/).

Available online: 30-07-2019
Date of reception: 08-03-2019

Date of acceptance: 12-03-2019

DOI: 10.24875/HGMX.M19000025
Rev Med Hosp Gen Mex. 2019;82(2):59-60

www.hospitalgeneral.mx 
as a result of the anti-rabies vaccine tested by Pasteur (1885), thus contributing to the birth of immunology.

At present, immunology is an autonomous science and its origins have been closely linked to microbiology. Its purpose is to study the defense responses developed by the host against the entry of microorganisms or foreign particles. Like other sciences, immunology was initiated by the mere empirical observation of certain events such as the case of ancient China, where it had been observed that people who had suffered from smallpox in their childhood did not acquire it later in life. In the $11^{\text {th }}$ century BC C., the Chinese were the first to attempt an application of these observations that indicated the induction of a protective state by means of a mild form of the disease: the inhalation of dust from crusts of smallpox caused a mild attack that conferred resistance to subsequent infections.

The English physician Edward Jenner (1749-1823), a medical student, made the first approach to immunization with rational criteria after his finding that the cowboys who had acquired vaccination smallpox (a benign form of the disease that only produced pustules in the hands) were not attacked by human smallpox.

Later Pasteur studying the bacteria responsible for avian cholera (later known as Pasteurella aviseptica), observed (1880) that the inoculation old virulent cultures of bacteria in chickens protected them from contracting the disease when they were later injected with virulent cultures. In this way, the first vaccine based on attenuated microorganisms was obtained. It was precisely Pasteur who gave the nature of the term "vaccine" (from Vacca: cow's Latin) in honor of Jenner's pioneering work.

At the end of the $19^{\text {th }}$ century, a prolific era in the field of microbiology and immunology, Mechnikov (1845-1916) discovered phagocytosis and Koch emphasized the importance of humoral mechanisms and working with the tubercle bacillus, what that we know as delayed hypersensitivity was discovered. Von Behring and Kitassato inoculated animals with diphtheria toxin and found that in the serum of these animals, a neutralizing substance of diphtheria toxin was produced and named it "antitoxin."

It was until the end of the century, the French and German schools called these fields of research "Immunological research" and began to consider two important approaches or theories of immunology: (1) the humoral, to study chemicals or antibodies elaborated by the cells and (2) the cellular, to study the biological effects of intact cells intervening in the host response to foreign elements.

After years of research, it was concluded that the homeostasis generated by the immune response was mediated by two subpopulations of cells or lymphocytes: helpers and suppressors.

With the arrival of molecular biology, subpopulations of lymphocytes were identified by means of surface molecules. Thus, we have the humoral immune response mediated by $B$ lymphocytes that recognizes antigens through the $B$ cell receptor and is associated with the CD19 coreceptor. The cellular immune response mediated by $\mathrm{T}$ lymphocytes recognizes antigens by means of the $T$ cell receptor and is associated with the CD3 polypeptide on the cell surface. Of this population of $\mathrm{T}$ cells, there are several subpopulations. At present, it is known that the product of $B$ and $T$ cells (lymphokines, interleukins, and chemokines) regulates the immune response.

Abounding in the topic, the products of microorganisms, both structural and metabolic, that participate in both the innate and the adaptive immune response are called "pathogen-associated molecular patterns" and both the surface and intracellular molecules of host cells are called "pattern of recognition receptors." 